\title{
Design and experiment of multi-row pneumatic precision metering device for rapeseed
}

\author{
Elebaid Jabir Ibrahim, Qingxi Liao*, Lei Wang, Yitao Liao, Lu Yao \\ (College of Engineering, Huazhong Agricultural University, Wuhan, Hubei 430070, China)
}

\begin{abstract}
The main objective of this study was to design a pneumatic disk with four-rows for planting rapeseed and to investigate its performance under several rotating speeds and vacuum pressure values. The effects of rotating speeds, vacuum pressure and rows on seed sucking and retaining were inspected. Six rotating speeds $(5 \mathrm{r} / \mathrm{min}, 10 \mathrm{r} / \mathrm{min}, 15 \mathrm{r} / \mathrm{min}, 20 \mathrm{r} / \mathrm{min}, 25$ $\mathrm{r} / \mathrm{min}$ and $30 \mathrm{r} / \mathrm{min}$ ) incorporated with the application of vacuum pressure were employed for detecting the optimum vacuum amount that was sufficient for seed sucking under each speed. These values of vacuum were found to be $1.1 \mathrm{kPa}, 1.25 \mathrm{kPa}$, $1.35 \mathrm{kPa}, 1.65 \mathrm{kPa}, 1.8 \mathrm{kPa}$ and $2.0 \mathrm{kPa}$, respectively. Moreover, a regression model was developed for predicting of vacuum pressure that corresponds with each rotating speed. Based on seed mass analysis, statistical differences were found at 5\% significance under the influence of speeds and negative pressure and existed also between and within rows according to Duncan's Test. The highest seed mass means of $3.17 \mathrm{~g}$ and $3.96 \mathrm{~g}$ were obtained by row 1 under the effects of speed and vacuum pressure, respectively, while the lowest means of $2.79 \mathrm{~g}$ and $3.05 \mathrm{~g}$ were attained by row 4 . Due to the influence of rows, important differences were occurred between row 1 (closer to the center of rotation) and row 4 (farther one), particularly under high speeds $(25 \mathrm{r} / \mathrm{min}$ and $30 \mathrm{r} / \mathrm{min})$. Results concluded that, pneumatic disk with multiple-rows could be satisfactorily used for seed sowing with a little variation in seed amount between rows without any seed damage. The rows of hole farther from plate center of rotation were obviously influenced by angular velocity and vacuum amount rather than the closer ones.
\end{abstract}

Keywords: precision seeder, metering device, performance, pneumatic, disk, multi-rows, rapeseed DOI: $10.25165 /$ j.ijabe.20181105.3544

Citation: Ibrahim E J, Liao Q X, Wang L, Liao Y T, Yao L. Design and experiment of multi-row pneumatic precision metering device for rapeseed. Int J Agric \& Biol Eng, 2018; 11(5): 116-123.

\section{Introduction}

Rape is the one of the most important oil crops worldwide. China is regarded as the largest producer of crop seeds with approximately $30 \%$ of the total world production ${ }^{[1]}$. There are different methods for rapeseed cultivation in China comprising seedlings transplanting, manual broadcasting and direct seeding. Transplanting pattern is considered the most conventional planting method which regarded as laborious, time-consuming, costly operation, as well as broadcasting, and strict in environmental requirement. Accordingly, these conditions should be met for avoiding irregular distribution and low productivity. Due to the migration of labor from productive areas to cities, it resulted in a scarcity of labor force to cultivate rapeseed. Furthermore, numerous crop sowing environments coupled with the shortage of seeding machines for the crop bring more cultivation difficulties for farmers. Therefore, the production necessitated the development of rapeseed mechanization ${ }^{[2]}$.

\section{Received date: 2017-06-07 Accepted date: 2018-03-15}

Biographies: Elebaid Jabir Ibrahim, PhD candidate, research interest: modern agricultural equipment design and control, precision planting technology, Email: ebaidjabir@gmail.com; Lei Wang, PhD candidate, research interest: precision maize planting technology, Email: 997931130@qq.com; Yitao Liao, PhD, Associate Professor, research interest: modern agricultural machinery and precision planting technology, Email: liaoetao@mail.hzau.edu.cn; Lu Yao, PhD candidate, research interest: modern agricultural equipment design and control, Email: yaolu1993@163.com.

*Corresponding author: Qingxi Liao, PhD, Professor, research interest: rapeseed planting and harvesting technology. College of Engineering, Huazhong Agricultural University, Wuhan 430070, China. Tel: +86-27-87282121, Email: liaoqx@mail.hzau.edu.cn.
Rapeseed described as a small size seed, round shape with soft skin, light in weight, rich in oil, and easily be damaged under low shear force $e^{[3,4]}$. These properties make it difficult to use the existing mechanical metering devices to perform precision seeding as to meet the agronomic requirements. It was found that using such devices tend to gather damage seeds around the metering holes and then block the nozzles of metering device ${ }^{[2]}$.

Precision planting was established by Datta since 1947 as to locate a single seeds at a desired distance in the soil ${ }^{[5]}$. The most significant constituent in seeding machine is metering device because it assures planter sowing performance ${ }^{[6]}$. Pneumatic metering technology is preferred for precision planting due to the little effect of air pressure on seed damage and meter seeds with different shapes and size, which made its application a broadly available in precision planting ${ }^{[7-10]}$. Due to the characteristics of rapeseed, a pneumatic precision metering device ${ }^{[11]}$ with negative and positive pressures ${ }^{[12,13]}$ were developed. Due to its remarkable advantages, the invented metering device was able to overcome the difficulties of sowing small-size seeds, and finally it was used with the 2BFQ- 6 combined direct seeder for rapeseed ${ }^{[14]}$.

Pneumatic type seeders are the most preferable among precision planters due to their observable advantages over mechanical types. They quietly meter seeds of different shapes and sizes, accurate in seed rate with lower seed damage, in addition to their extensive application ${ }^{[15,16]}$. Furthermore, Precision planting decreases excessive use of seeds by reason of uniform distribution and avoid seed rolling in the furrow which results in a specific seed number per unit length. Moreover, they provide homogeneous plants germination which makes easier to perform subsequent operations such as weeding and harvesting with lower $\operatorname{cost}^{[17]}$. The seeds physical properties, structural and operating 
parameters and soil environment are regarded to be the most important parameters related to the performance of precision planters ${ }^{[18]}$. Nevertheless, there are many factors affecting the performance of metering device in the field, thus researchers exerted efforts to accomplish desired performance through experiments.

Several studies were previously carried out to investigate the performance of precision planters. They provided valuable information about the performance of precision metering mechanism either in the laboratory or field. These researches were mostly focusing on vacuum pressure applied to the plate which regarded the most widespread metering system in precision planters. Singh et al. ${ }^{[19]}$ studied the impact of rotating speed, negative pressure and shape of nozzle entrance of vacuum plate and assessed the precision indices (skip, multiple and quality of feed index). On the other hand, they supposed that the proper nozzle diameter for cotton seeds precision was $2.5 \mathrm{~mm}$. Not only but also they reported that the metering unit with a speed of $0.42 \mathrm{~m} / \mathrm{s}$ and a vacuum of $2 \mathrm{kPa}$ resulted in values of $94.7 \%$ and $8.6 \%$ as quality of feed index and coefficient of variation, respectively ${ }^{[19]}$. The operating parameters of a vacuum precision planter, namely, the plate applied vacuum, diameter of holes and the peripheral speed of the plate were appraised. In this trial the response surface methodology was applied to explore the performance of seed distribution consistency. Laboratory data attained was separated into three different groups as to estimate the values of the three spacing indices. The negative pressure of about $5.5 \mathrm{kPa}$ and hole diameter of $3 \mathrm{~mm}$ were found to be the best values for precision of cotton seeds ${ }^{[20]}$. A pressurized-type row planter was evaluated at three peripheral speeds $(0.16 \mathrm{~m} / \mathrm{s}, 0.23 \mathrm{~m} / \mathrm{s}$ and $0.31 \mathrm{~m} / \mathrm{s}$ ) with their corresponding planter working speeds $(1.33 \mathrm{~m} / \mathrm{s}, 2.0 \mathrm{~m} / \mathrm{s}$ and $2.7 \mathrm{~m} / \mathrm{s})$ under field test using cotton and maize seeds. Their tests declared that the variation in seed spacing proportionally increased with the linear velocity ${ }^{[21]}$.

The technique of high-speed camera system was applied to investigate seed distribution regularity and velocity of dropping. The seed preciseness resulted from camera system was matched with that of greased -belt stand which considered as a reference. Under all tests with camera system, no missed seeds were occurred $^{[22]}$. An exploration of the effectiveness of air-suction precision planter to assess seed pick-up capability was conducted using axial and radial seed capture distance and size of effective pick-up area ${ }^{[23]}$. A complex flow rate of paddy rice kernels was conducted using a horizontally rotating cylinder with holes on its periphery, while Artificial Neural Network method and regression were utilized for analysis. The most suitable cylinder design was found to be 36 nozzles of $6 \mathrm{~mm}$ diameter on the drum perimeter along with the angular velocity of $61 \mathrm{r} / \mathrm{min}^{[24-26]}$. The bench test stand integrated with computerized camera system for seed observing to explore the best performance of pneumatic disk for rapeseed distribution accuracy was employed. Results revealed that no seed damage was detected, while the precision indices (quality feed, multiple and miss index) were outstandingly influenced by angular velocity and vacuum amount ${ }^{[1]}$. Zhan et al. ${ }^{[27]}$ studied the performance of a pressurized planter of a cylindrical type for rapeseed distribution accuracy. They applied the method of computational fluid dynamics (CFD) software for computing forces acting on free fall seeds, thus they found out the seed movement and dropping trajectories using several numerical equations. Their attempts incorporated with belt test stand gave rise to reasonable findings. Seed suction of pneumatic metering device for rapeseed was inspected; accordingly, some findings were obtained about nozzles diameter, number, radius of orifice and plate peripheral speed ${ }^{[28]}$. Wu et al. ${ }^{[29]}$ constructed Rapeseed pneumatic metering device. It is parameters such as vacuum pressure, hole diameter, holes number and angular velocity, in addition to the air chamber and optimum structural parameters were closely studied ${ }^{[2]}$.

The recently developed rapeseed pneumatic metering devices such as vertical disk-type ${ }^{[18]}$ and inside-filling drum ${ }^{[30]}$ are capable to plant only one row at a time, this may result in complicated transmission and pressure systems of rapeseed planter. On the other hand, the outer-surface, multi-row, pneumatic cylinder ${ }^{[31,32]}$ requires a higher vacuum pressure to overcome the effect of centrifugal and gravity forces. Additionally, the inside-filling cylinder-type centralized metering device ${ }^{[33]}$, consume relatively higher negative pressure compared with the recently invented device. From another view, several types of currently available precision planters of plate type have been constructed with multimetering units and provided with separate metering devices for sowing separate rows. In other words, each metering plate is used individually in a separate unit for metering only one row. This in turn make the whole planter cumbersome with inconvenient situations, complex, require a considerable maintenance, expensive to produce and inflexible to use for planting narrow row spacings. Furthermore, for a planter containing a large number of metering units, the assembly is complex, hinders the individual adjustment of the plates and requires complicated pressure and transmission systems. Inflexible to perform narrow row spacing necessitates an additional operation; otherwise the crop will result in an undesired plant establishment. As a result, all these things collectively result in high cost either for the entire planter components or in results after sowing operation.

Due to all mentioned problems, it was intended through this work to improve upon the problems and deficiencies of previously invented devices. Whereas, the main objective was to create a seed metering device using a single metering disk for metering multi-rows as to eliminate the use of separate metering unit for each row, and consequently remove any unnecessary part that may bring device complexity. Therefore, the present prototype varies from the conventional plate type with a single row in its capability to meter four rows of seeds simultaneously without damage, applicable to various types of seeds with different shape and size, can eliminate planter transmission and pressure system complication, able to achieve both very close and wide row spacings, need low working pressure which decrease power consumption, effective with less expensive construction and maintenance, and it is described as: compact, light, simple, easy and quick to use. Further advantages could be drawn from this invention: 1) it provide an option to select the desired number of rows to be metered (within 1-4 rows); 2) it was able to achieve same seed dropping time of rows; 3) rows number can be multiplied by adding another plate to the other side of the air chamber after modification; and 4) it could be provided with a method for adjusting seed pick-up similarity of the rows.

The study aiming at a development of multi-row, pneumatic disk metering device for sowing rapeseed and examine its performance under different levels of vacuum pressure and rotational speeds in order to:

1) Detect the capability of the plate for seed pick-up with appropriate vacuum amount through the different rows levels. Investigate the consistency of seed pick-up under the four rows in terms of seed mass. 
2) Determine the optimum vacuum pressure value that could be adequate for seed capture under corresponding operating speeds.

3) Modify and optimize of the device working and design parameters for advanced performance investigation.

\section{Materials and methods}

\subsection{Physical properties of tested rapeseed}

One of the most important factors in determining the design and working parameters is the seeds physical properties. Table 1 show the main dimensions, sphericity and one thousand seed weight of rape. One hundred samples were randomly selected for measuring dimensions using a vernier calliper with a sensitivity of $0.01 \mathrm{~mm}$. A digital balance with an accuracy of $0.01 \mathrm{~g}$ was employed for measuring seed mass.

Table 1 Physical characteristics of rapeseed (Hua Oil Hybridization 62)

\begin{tabular}{lcc}
\multicolumn{1}{c}{ Physical properties } & Mean & Standard error \\
\hline Length $l / \mathrm{mm}$ & 2.03 & 0.107 \\
Width $w / \mathrm{mm}$ & 1.90 & 0.124 \\
Thickness $t / \mathrm{mm}$ & 1.81 & 0.078 \\
Sphericity $/ \% *$ & 96.42 & 1.356 \\
Thousand seed mass $/ \mathrm{g}$ & 4.6 & - \\
$*$ Calculated as & $\frac{(l w t)^{1 / 3}}{l} \times 100 \%$ & \\
\hline
\end{tabular}

\subsection{Structural parts and working principle of metering device}

A prototype metering unit using vertical plate with four-rows was designed for sowing rapeseed according to variable rotating speed and vacuum amount. One side of the plate was connected to air pressure to imply vacuum at seed sucking stage and positive pressure at release points, while the other face was attached to seed supply source and seed dropping tubes. Figure 1a showing the main components of the metering device and Figure $1 \mathrm{~b}$ explain the air chamber two cavities.

The air chamber was split into two cavities; the larger one was connected to the vacuum pump, while the smaller receive positive pressure. The top edge of positive pressure cavity was machined to be in a horizontal level (Figure 1b), in order to allow positive pressure connects to the four nozzles of rows simultaneously when aligning at release points as to secure same dropping time.
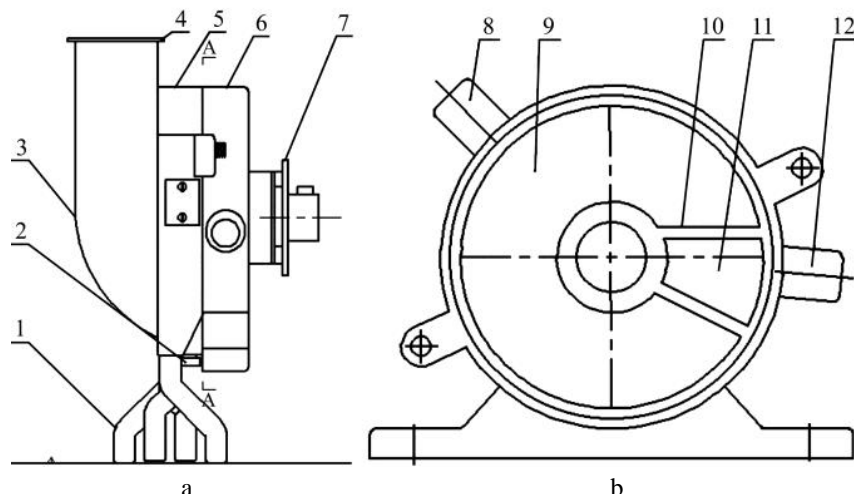

1. Seed tubes 2. Seed discharge nut 3. Seed box 4. Seed box cover

5. Plate cover 6. Pressure chamber 7. Driving gear 8. Vacuum inlet

9. Vacuum cavity 10. Horizontal top edge of positive cavity 11. Positive pressure cavity 12. Positive pressure inlet

Figure 1 Schematic diagram of multi-rows pneumatic plate metering device

The seed disk was $160 \mathrm{~mm}$ in diameter, perforated with 40 circular holes of $1.2 \mathrm{~mm}$ diameter each around its center of rotation constituting four circles of holes and hence four rows for performance evaluation as shown in Figure 2. The distance of the first hole row from the center of the plate was $30 \mathrm{~mm}$, while the gap between adjacent hole rows was $14 \mathrm{~mm}$.

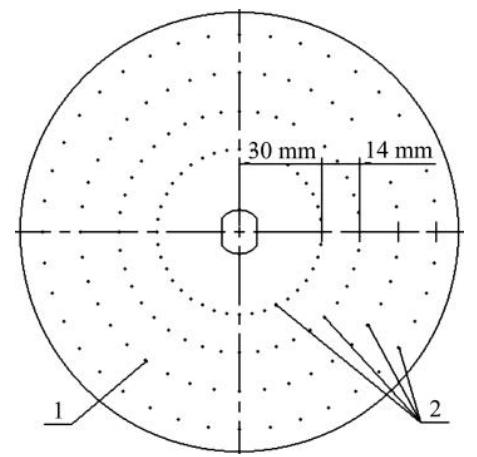

Note: 1 . Hole diameter $(1.2 \mathrm{~mm}) ; 2$. The four hole rows

Figure 2 Metering plate with four rows of metering nozzles around its center of rotation

According to the angle of repose of rapeseed, a special seed box was equipped with an angle of $28^{\circ}$ at the bottom and seed feeding slot to provide and keep seed level accessible for all metering nozzles under seed filling stage. This slot was cut in the inner wall of the box with an oblong shape starting from the bottom upwards (Figure 3). The height and width of the cut were $80 \mathrm{~mm}$ and $25 \mathrm{~mm}$, respectively, to provide smooth seed flow and be available under the four levels of metering holes. Furthermore, a sliding plastic sheet was mounted on seed supply slot of the seed box which could be drawn up and downwards to determine the level of seed flow to the metering plate. Consequently, it can determine the number of rows needs to be utilized for seed metering process.

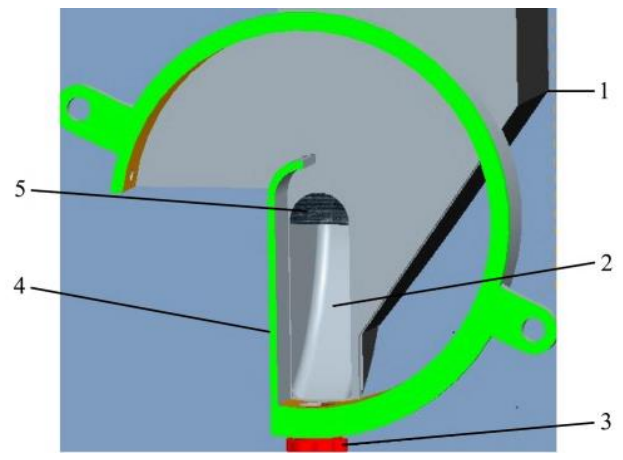

1. Seed box 2. Seed feeding groove 3. Seed discharge nut 4. Sliding sheet 5. Seed barrier

Figure 3 Seed box with seed supply slot and sliding sheet for seed flow control

The seed tubes as in Figure 4 were made of rigid plastic using three dimension printing machine (3D printer). They built as one unit in a rectangular box divided internally into four parts to create a separate groove for each row planting. The lower ends of these parts were turned into equal round tubes with $12 \mathrm{~mm}$ diameter each and $14 \mathrm{~mm}$ between adjacent tubes. Each tube was bent with an angle of $135^{\circ}$ from the vertical level downwards as to allow smooth seed dropping. The direction of each angle was made to be opposite to that of the adjacent one in order to make easy for connecting dropping hoses. The whole unit is connected to the frame with its seed tubes aligning with the disk metering holes during dropping stage.

The metering system is operated through a solid shaft rotating by the means of sprocket and chain driven electric motor. Seeds from seed box bottom flow to be in contact with the metering plate 
surface. Under the absorption of negative pressure, seeds are picked up and adhere to the nozzles on the rotating plate. Further rotation of the plate make the nozzles reach the release points where vacuum is changed to positive pressure and seeds fall into seed tubes under gravity force and positive differential pressure.
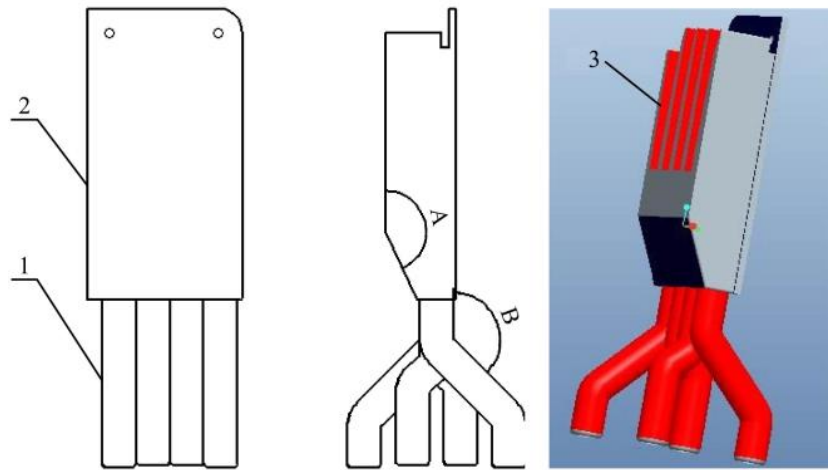

Notes: 1. Seed tubes; 2. Rectangular box; 3. Separators. A is $155^{\circ}$; B is $135^{\circ}$ Figure 4 Side views of seed tube unit and its main dimensions

\subsection{Theory of seed metering operation}

Seed metering operation should be achieved under three essential stages aiming at accurately place seeds at the desired spacing. The first stage is the capture of seeds by the vacuum plate and this should be done without seed missing, doubling or damage. The second is the seed holding and retaining stage which requires sticking of seeds on the nozzle during plate rotation until arrives at the dropping points. The last stage is the release of seeds from the plate and drops them down. Figure 5 display the three stages and corresponding angles according to the device structure.

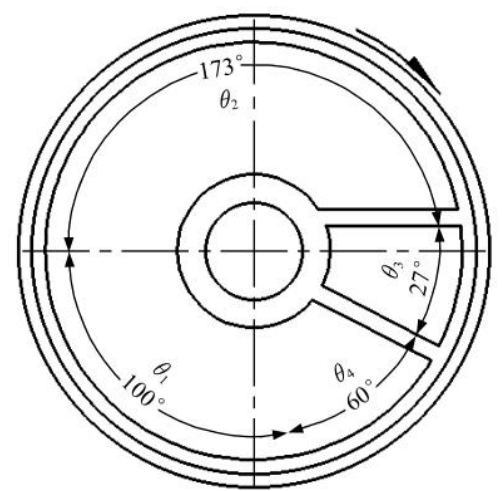

Note: $\theta_{1}$ is seed sucking angle, $\left(^{\circ}\right) ; \theta_{2}$ is seed retaining angle, $\left({ }^{\circ}\right) ; \theta_{3}$ is the dropping angle, $\left({ }^{\circ}\right) ; \theta_{4}$ is the rest area, $\left({ }^{\circ}\right)$.

Figure 5 Sketch diagram for seed metering operation

The operation of seed suction through the hole is an important issue. Vacuum runs in radial direction through the hole, whereas, air flow lines constitute a semi-sphere envelope. Pressure speed rises up as the radius of the envelope decrease. The speed of air $\left(V_{r}\right)$ at a space of $\left(r_{1}\right)$ from hole center could be estimated by Equation (1).

$$
V_{r_{1}}=\frac{r_{2}^{2}}{r_{1}^{2}} \cdot \frac{\sqrt[\alpha]{\frac{2 g p}{\gamma}}}{2}
$$

where, $r_{2}$ is the metering hole radius; $\alpha$ is the flow coefficient (assume to be 0.7); $\gamma$ is the specific weight of air $\left(11.2 \mathrm{~N} / \mathrm{m}^{3}\right.$ at $20^{\circ} \mathrm{C}$ and $\left.96 \mathrm{kPa}\right) ; p$ is the vacuum pressure, $\mathrm{N} / \mathrm{m}^{2} ; g$ is gravity acceleration, $\mathrm{m} / \mathrm{s}^{2}$.

The air velocity through the center of the hole $\left(V_{r_{2}}\right)$ could be computed by Equation (2).

$$
V_{r_{2}}=\sqrt[\alpha]{\frac{2 g p}{\gamma}}
$$

Vacuum plate peripheral speed of $V_{p}$ and the forward speed of the planter $V_{f}$ could be measured using Equations (3) and (4).

$$
\begin{gathered}
V_{p}=\frac{\pi d n_{p}}{60} \\
V_{f}=\frac{n_{p}}{60} k Z_{t}
\end{gathered}
$$

where, $d$ is the plate diameter $(\mathrm{m}) ; n_{p}$ is $\mathrm{r} / \mathrm{min}$ of the plate $\left(\mathrm{min}^{-1}\right) ; k$ is holes number in the plate; and $Z_{t}$ is the theoretical seed spacing (m). If $k$ is replaced by $\pi d / l$ into Equation (3), the value of $V_{f} / V_{p}$ become as in Equation (5).

$$
\frac{V_{f}}{V_{p}}=\frac{Z_{t}}{l}
$$

where, $l$ is arc distance between adjacent holes in the plate and $m$ is the velocity ratio.

Under the situation of zero-slippage, forward speed $\left(V_{f}\right)$ is equal to drive wheel peripheral speed $\left(V_{w}\right)$. Accordingly, theoretical seed distance $\left(Z_{t}\right)$ is calculated due to travel wheel $(D)$, transmission ratio $(i)$ and hole number in the plate $(k)$ as in Equation (7).

$$
Z_{t}=\frac{\pi D}{i k}
$$

\subsection{Experiment description and statistical method}

In this study, six levels of both rotating speeds $(5 \mathrm{r} / \mathrm{min}, 10$ $\mathrm{r} / \mathrm{min}, 15 \mathrm{r} / \mathrm{min}, 20 \mathrm{r} / \mathrm{min}, 25 \mathrm{r} / \mathrm{min}$ and $30 \mathrm{r} / \mathrm{min}$ ) and vacuum pressure $(0.3 \mathrm{kPa}, 0.5 \mathrm{kPa}, 1 \mathrm{kPa}, 1.2 \mathrm{kPa}, 1.5 \mathrm{kPa}$ and $1.8 \mathrm{kPa})$ were separately utilized to investigate the influence of each variable on seed pick-up in terms of seed mass. In addition, each of these rotating speeds (RS) was incorporated with negative pressure (NP) to determine the ideal amount of vacuum that could be sufficient for seed sucking and retaining under the four rows without missing. Under each speed and through all tests, the prototype was operated for one minute and seed weight for separate rows per each discharge tube was obtained. The experiment was replicated five times and then seed means were attained.

SAS statistical software package was employed for data arrangement and analysis. Duncan's multiple-range test was used to recognize the effect of angular velocity, negative pressure on seed pick-up under the four row levels and means significance between and within rows.

\section{Results and discussion}

\subsection{Effect of rotating speed (RS) on seed pick-up}

The influences of rotating speed on seed pick-up of the multirow pneumatic disk metering device under constant vacuum amount are shown in Table 2. The table shows that as the plate angular velocity increase, the pick-up seed mass of the rows also increase. In other words, when the plate rotating speed increases, the number of dropping seeds also increases through all rows. However, under the mentioned vacuum amount (1 $\mathrm{kPa})$, an increase in the speed resulted in increased variation between rows seed suction. According to this fact, a specific vacuum is able to suck seeds under certain speed properly and if any more increase in speed vacuum will result in more missing or will be insufficient to suck more seeds. This means that each speed requires a particular amount of vacuum pressure to suck seeds uniformly. This result is similar with the advanced pneumatic seed-metering units ${ }^{[18,20,34]}$. 
As could be seen from Table 2, the seed mass was considerably differing due to the variation in plate rotational speeds. Based on the grain mass, there were significant differences at 5\% significance between seed weight means at different speeds. The highest value (4.96 g) was obtained from the highest speed (30 r/min), while the lowest amount $(0.826 \mathrm{~g})$ attained by the slowest speed $(5 \mathrm{r} / \mathrm{min})$. It could also be noticed that there were important differences between rows means under collective vacuums due to Duncan's test, whereas, $3.17 \mathrm{~g}, 2.77 \mathrm{~g}, 2.85 \mathrm{~g}$ and $2.79 \mathrm{~g}$ were obtained by row $1,2,3$ and row 4, respectively. Row 2 and 4 resulted in no significant difference with the means of 2.77 and 2.79, respectively. Means variations were also found within and between rows with same or different angular velocity. The influence of the same speed on rows seed mass is declared by coefficient of variation $\mathrm{CV}$. The variation in rows seed weight at lower speeds $(5 \mathrm{r} / \mathrm{min}, 10 \mathrm{r} / \mathrm{min}$ or $15 \mathrm{r} / \mathrm{min})$ might be referred to different multiple seed pick-up by the rows levels due to vacuum pressure, while at higher speeds it could be attributed to variable multiple and/or missing seeds due to high speed. The increase in speed negatively affected rows pick-up consistency as could be clearly observed from the speed of 25 and $30 \mathrm{r} / \mathrm{min}$. The reason for that may returned to insufficient interaction time between the metering hole and seeds within vacuum zone which may result in miss or non-sucking seeds. This result is corresponding with other seed-metering devices ${ }^{[18,34]}$. The coefficient of variation for rows means at different speed levels ranged from $5.34 \%$ to $8.90 \%$ which indicates an acceptable results.

\subsection{Effects of negative pressure (NP) on seed pick-up}

Table 3 showed the influence of vacuum pressure (when the speed held constant) on seed pick-up regularity of the rows and their variation coefficients. It was found that the negative pressure under constant rotating speed influenced seed mass at $5 \%$ significance. The variation in seed weight means under different vacuum levels was significant according to the results of Duncan's test as shown in the Table. Vacuum pressure was proportionally affected seed pick-up mass; therefore, an increase in vacuum pressure provided an increase in seed pick-up. This result was in line with that obtained from single-row vertical disk device and inside-filling seed-metering cylinder ${ }^{[18,33]}$. Generally, a decrease in vacuum pressure reduced the number of adhering seeds; while an increase resulted in more seeds adhere to the nozzle entrance. The amount of negative pressure that meets the corresponding rotating speed was found to be quite similar with the single-row vertical disk and not largely different from inside-filling seed-metering cylinder $^{[18,33]}$.

Once again, Table 3 showed that seed pick-up continued to increase when angular velocity was held constant and vacuum pressure was gradually increased from $-0.3 \mathrm{kPa}$ to $-1.8 \mathrm{kPa}$. The table revealed that changing of vacuum amount had greater effect on seed mass in separate rows with different vacuum pressure (as explained by small letters), between rows under collective vacuum (as given in capital letters), under collective rows with same vacuum (as presented by capital bold letters) and between rows with same vacuum amount. As the vacuum gradually increased, the seed pick-up also increased, whereas the highest seed mass mean $(3.823 \mathrm{~g})$ under collective rows was achieved at $1.8 \mathrm{kPa}$ vacuum pressure, while the lowest mean $(2.327 \mathrm{~g})$ was obtained at $0.3 \mathrm{kPa}$ vacuum amount.

Table 2 Effect of rotating speed on seed pick-up mass under the four rows

\begin{tabular}{|c|c|c|c|c|c|c|c|}
\hline \multirow{2}{*}{$\begin{array}{l}\text { Rotating speed } \\
\qquad / \mathrm{r} \cdot \mathrm{min}^{-1}\end{array}$} & \multirow{2}{*}{$\begin{array}{c}\text { Constant vacuum } \\
\qquad / \mathrm{kPa}\end{array}$} & \multicolumn{5}{|c|}{ Seed mass means/g } & \multirow{2}{*}{$\mathrm{CV}$} \\
\hline & & Row 1 & Row 2 & Row 3 & Row 4 & DMRT & \\
\hline 5 & 1 & 0.878 & 0.776 & 0.808 & 0.844 & $0.8265 \mathrm{~F}$ & 5.3433 \\
\hline 10 & 1 & 1.788 & 1.470 & 1.580 & 1.740 & $1.644 \mathrm{E}$ & 8.9040 \\
\hline 15 & 1 & 2.658 & 2.262 & 2.430 & 2.346 & $2.424 \mathrm{D}$ & 7.0301 \\
\hline 20 & 1 & 3.684 & 3.290 & 3.350 & 3.236 & $3.390 \mathrm{C}$ & 5.4418 \\
\hline 25 & 1 & 4.490 & 3.992 & 4.058 & 4.084 & $4.156 \mathrm{~B}$ & 5.4381 \\
\hline 30 & 1 & 5.562 & 4.856 & 4.892 & 4.534 & $4.961 \mathrm{~A}$ & 8.7035 \\
\hline \multicolumn{2}{|c|}{ DMRT } & $3.176 \mathrm{a}$ & $2.774 \mathrm{c}$ & $2.852 \mathrm{~b}$ & $2.797 \mathrm{c}$ & & \\
\hline
\end{tabular}

Notes: Capital and small letters were used for describing means significance under the speeds and rows effects, respectively. Means with the same letters are not significantly different at 5\% level, by Duncan's Multiple Range Test (DMRT).

Table 3 Effects of vacuum pressure on seed pick-up mass under the four rows

\begin{tabular}{|c|c|c|c|c|c|c|c|}
\hline \multirow{2}{*}{$\begin{array}{l}\text { Negative pressure } \\
\qquad / \mathrm{kPa}\end{array}$} & \multirow{2}{*}{$\begin{array}{l}\text { Constant rotating } \\
\text { speed } / \mathrm{r} \cdot \mathrm{min}^{-1}\end{array}$} & \multicolumn{5}{|c|}{ Seed mass means/g } & \multirow{2}{*}{$\mathrm{CV}$} \\
\hline & & Row 1 & Row 2 & Row 3 & Row 4 & DMRT & \\
\hline 0.3 & 20 & $2.842 \mathrm{f}$ & $2.328 \mathrm{~d}$ & $2.100 \mathrm{~d}$ & $2.032 \mathrm{~d}$ & $2.327 \mathrm{~F}$ & 15.775 \\
\hline 0.5 & 20 & $3.598 \mathrm{e}$ & $3.158 \mathrm{c}$ & $3.090 \mathrm{c}$ & $3.012 \mathrm{c}$ & $3.214 \mathrm{E}$ & 8.167 \\
\hline 1.0 & 20 & $3.820 \mathrm{~d}$ & $3.486 \mathrm{a}$ & $3.230 \mathrm{bc}$ & $3.128 b c$ & $3.416 \mathrm{D}$ & 9.033 \\
\hline 1.2 & 20 & $4.192 \mathrm{c}$ & $3.330 \mathrm{~b}$ & $3.272 \mathrm{~b}$ & $3.184 b$ & $3.494 \mathrm{C}$ & 13.417 \\
\hline 1.8 & 20 & $4.778 \mathrm{a}$ & $3.530 \mathrm{a}$ & $3.448 \mathrm{a}$ & $3.536 \mathrm{a}$ & $3.823 \mathrm{~A}$ & 16.686 \\
\hline \multicolumn{2}{|c|}{ DMRT } & $3.967 \mathrm{~A}$ & $3.212 \mathrm{~B}$ & $3.098 \mathrm{C}$ & $3.057 \mathrm{C}$ & & \\
\hline
\end{tabular}

Notes: Capital and small letters used for describing means significance under negative pressure and rows effects, respectively. Means with the same letters are not significantly different at 5\% level, by Duncan's Multiple Range Test (DMRT).

Important differences were existed also between rows under collective vacuum amounts, whilst, the values of $3.967 \mathrm{~g}, 3.212 \mathrm{~g}$, $3.098 \mathrm{~g}$ and $3.057 \mathrm{~g}$ were reported for row 1, 2, 3 and 4, respectively. Moreover, significant variations were happened through each row with different pressure levels as explained by small letters (a, b, c, d, e and f) vertically. Means dissimilarity was also occurred between some rows under same vacuum amounts; where, some of them were significantly differed while others were not (as indicated by $\mathrm{CV}$ ). This may attributed to unequal rows seed pick-up due to irregular vacuum passes through the rows holes level, or sometimes, 
resulted from frequent multiple seeds.

Although row1 is the farthest one from vacuum inlet, but it resulted in the highest seed weight under all vacuum levels compared with the other rows. That may returns to the peripheral velocity which is comparatively lower than other rows and/or to the enclosed vacuum around the plate center that may produced relatively higher vacuum pressure passed through this row holes. In the contrary, the lowest seed mean was obtained by row 4 $(3.057 \mathrm{~g})$ but was not significantly differ from row 3 .

\subsection{Effects of rotating speed (RS) and negative pressure (NP) on seed pick-up}

Figure 6 showed the interaction of negative pressure and rotating speed of the metering device on seed pick-up performance. To scrutinize the required vacuum pressure versus each plate rotating speed, variety of attempts were made for verifying the most favorable value of negative pressure that could be sufficient for seed pick-up. The optimum vacuum amount was determined under each rotating speed according to seed sucking and holding capacity. It was found that the required vacuum for seeds capture under the four rows was proportional with the angular velocity, this result agrees with the previous research ${ }^{[18,35]}$. Accordingly, an increase in rotating speed required an increase in vacuum amount and vice versa. Thus, a linear regression model was developed for predicting of rapeseed pick-up pressure when the device was operated with different rotating speeds as presented in Figure 6. The figure is clearly showing the optimal values of vacuum that corresponds well with the angular velocities. It was observed that during operation negative pressure lower than the optimal value under each speed resulted in some empty nozzles, while higher than these levels produced more multiples, this was agree with that stated by Searle et al. ${ }^{[9]}$

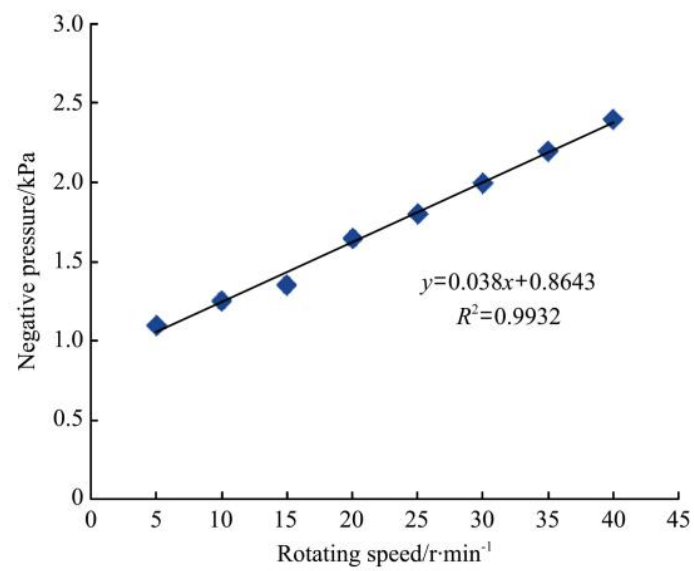

Figure 6 Relationship between angular velocity and corresponding negative pressure for seed pick-up under the four rows

\subsection{Effects of RS, NP and rows on seed pick-up mass}

Table 4 displaying seed mass obtained from the four rows under different angular velocities and corresponding optimum negative pressure. Analysis of results revealed that seed pick-up under the four rows was affected by combined rotating speed and vacuum pressure, in addition to the rows of the plate. Some statistical differences between rows with the same vacuum and same speed were occurred. As could be noticed from the Table 4, seed suction and retaining under the four rows were affected by high rotating speed $(20 \mathrm{r} / \mathrm{min}, 25 \mathrm{r} / \mathrm{min}$, and $30 \mathrm{r} / \mathrm{min})$ and vacuum pressure around the nozzles rather than low speeds $(5 \mathrm{r} / \mathrm{min}$, $10 \mathrm{r} / \mathrm{min}$ and $15 \mathrm{r} / \mathrm{min}$ ), particularly through the hole row farther from the center of rotation (row 4) compared with the closer ones.
The variation in the means of rows under same vacuum pressure and same speed might be attributed to separate or combined two factors; either to the variation in peripheral speeds of hole rows and /or inadequate negative pressure resulted from air leakage at the plate peripheral edge that may produced an insufficient amount for seed retaining which results in a few sticking or missing seeds. On the other hand, multiple seed occurs due to variation in seed size (ungraded seeds) or if none of them is capable to entirely close the metering of hole. In some cases, no seeds were picked up by the nozzles, whilst, other nozzles lift up more than one seed simultaneously. This result was found to be similar to that reported by Barut et al. ${ }^{[36]}$

Table 4 Effects of rotating speed, negative pressure and rows on seed pick-up mass

\begin{tabular}{|c|c|c|c|c|c|c|c|}
\hline \multirow{2}{*}{ RS@NP } & \multicolumn{4}{|c|}{ Mean seed weight/g } & \multirow{2}{*}{$\begin{array}{l}\text { *Theoretical } \\
\text { seed mass/g }\end{array}$} & \multirow{2}{*}{$\mathrm{CV}$} & \multirow{2}{*}{ MSE } \\
\hline & Row 1 & Row 2 & Row 3 & Row 4 & & & \\
\hline $05 @ 1.10$ & 1.152 & 1.140 & 1.132 & 1.120 & 0.920 & 1.1853 & 0.0228 \\
\hline $10 @ 1.25$ & 2.278 & 2.272 & 2.164 & 2.160 & 1.840 & 2.9437 & 0.0344 \\
\hline $15 @ 1.35$ & 3.400 & 3.350 & 3.172 & 3.070 & 2.760 & 4.6381 & 0.0589 \\
\hline $20 @ 1.65$ & 4.570 & 4.542 & 4.396 & 4.166 & 3.680 & 4.1826 & 0.0563 \\
\hline $25 @ 1.80$ & 5.850 & 5.590 & 5.154 & 4.800 & 4.600 & 8.6929 & 0.1487 \\
\hline $30 @ 2.00$ & 6.830 & 6.430 & 5.660 & 5.030 & 5.520 & 13.3947 & 0.1270 \\
\hline
\end{tabular}

Note: MSE is for means comparison between rows.

* Theoretical seed mass is the weight of seeds calculated according to number of holes in the plate and its rotating speed, assuming that each hole carry only one seed each revolution and their weight was predicted according to the thousand seed mass $(4.6 \mathrm{~g})$.

It is clear to be noticed from Figure 7 that the mean seed mass between rows was seemed to be consistent under low speed and start fluctuating as the speed increase, but it was considerably varied at high speeds. However, seed mass per each row under all speeds was found to be more than theoretical weight. Theoretical weight is the weight of seeds according to the thousand seed mass which could be obtained by multiplying the rotating speed by plate hole number assuming that each hole hold only on seed each time. As it could be perceived from Table 4 , all rows under all speeds resulted in higher seed mass than the theoretical. These results indicated that some holes were sometimes picking up more than one seed. However, the worst seed mass was obtained from row4 with the speed of $30 \mathrm{r} / \mathrm{min}$ because it resulted in lower grain mass $(5.03 \mathrm{~g})$ than theoretical $(5.52 \mathrm{~g})$ which denoted some missing seeds. Another thing could also be observed from Figure 4 that seed mass decreases as the nozzles row existing farther from the disk center of rotation and vice versa.

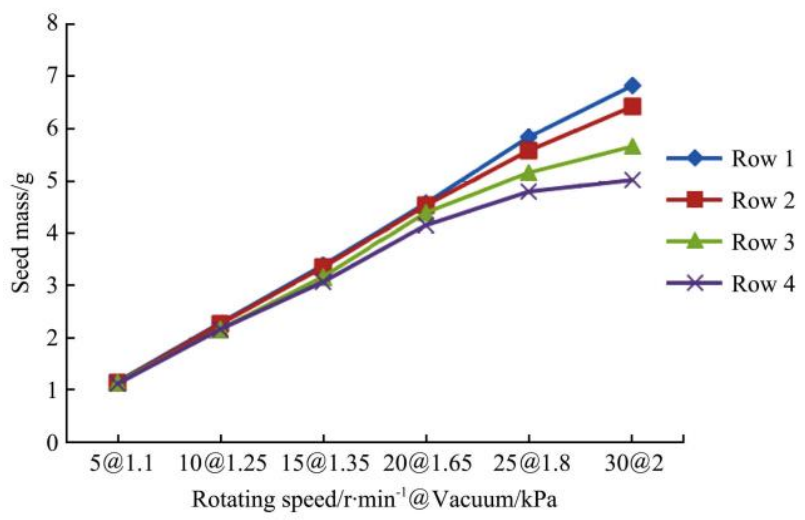

Figure 7 Effects of combined rotating speed and corresponding vacuum on seed pick-up under the four rows 


\section{Conclusions}

This study was conducted to investigate the performance of multi-rows pneumatic plate for rapeseed metering accompanied with the effects of angular velocity, negative pressure and hole rows on seed sucking consistency. Research results were concluded as follows:

1) Seed pick-up operation in terms of seed mass under the four rows was rather different due to variation in rows peripheral speeds, particularly with the rotating speed of more than $25 \mathrm{r} / \mathrm{min}$, but the plate was found to be acceptable for rapeseed metering with completely absence of broken seeds;

2) As the row of holes is farther from plate center of rotation, its ability for seed capture reduces compared with the adjacent ones;

3) The most appropriate the highest rotating speed was found to be $20 \mathrm{r} / \mathrm{min}$ with the vacuum of $1.65 \mathrm{kPa}$, because it resulted in rows seed means more than theoretical weight which indicates no missing seeds, in addition, it provided the closer rows means rather than $25 \mathrm{r} / \mathrm{min}$ and $30 \mathrm{r} / \mathrm{min}$;

4) Statistical analysis revealed that the seed pick-up operation was significantly affected by rotating speed, negative pressure and hole rows;

5) It is strongly recommended that the plate metering hole should be perforated with a cone shape entrance as to secure picking only one seed that is capable to completely close the entrance and then successfully utilized for precision metering.

\section{Acknowledgements}

This work was financially supported by the National Natural Science Foundation of China (Grant No.51575218 and No.51405180). Thanks and appreciations are extended to you all for your support. Appreciations could also be extended to laboratory mates for their help and cooperation.

\section{Nomenclatures}

\begin{tabular}{ll}
\hline$d$ & plate diameter, $\mathrm{m} ;$ \\
$D$ & travel wheel diameter, $\mathrm{m} ;$ \\
$g$ & gravity acceleration, $\mathrm{m} / \mathrm{s}^{2} ;$ \\
$i$ & transmission ratio; \\
$k$ & holes number in metering plate; \\
$l$ & arc distance between adjacent holes, $\mathrm{mm} ;$ \\
$m$ & plate velocity ratio; \\
$n_{p}$ & rotate speed of the plate, $\mathrm{r} / \mathrm{min} ;$ \\
$p$ & vacuum pressure, $\mathrm{N} / \mathrm{m}^{2}$ \\
$r_{2}$ & metering hole radius, $\mathrm{mm} ;$ \\
$V_{f}$ & speed of the planter, $\mathrm{km} / \mathrm{h} ;$ \\
$V_{p}$ & vacuum plate peripheral speed forward, $\mathrm{m} / \mathrm{s} ;$ \\
$V_{r_{1}}$ & air velocity at distance $r_{1}$ from hole center, $\mathrm{m} / \mathrm{s} ;$ \\
$V_{r_{2}}$ & air velocity through hole center, $\mathrm{m} / \mathrm{s} ;$ \\
$\alpha$ & air flow coefficient $(0.7) ;$ \\
$\gamma$ & specific weight of air $\left(11.2 \mathrm{~N} / \mathrm{m}^{3}\right.$ at $20^{\circ} \mathrm{C}$ and $\left.96 \mathrm{kPa}\right) ;$ \\
$Z_{t}$ & Theoretical seed spacing, $\mathrm{m}$. \\
\hline
\end{tabular}

\section{[References]}

[1] Liao Q X, Li J B, Qin G L. Simulation analysis on air current field of pneumatic precision metering device for rapeseed. Transaction of the CSAM, 2009; 40(7): 78-82. (in Chinese)

[2] Yu J J, Liao Y T, Cong J L, Yang S, Liao Q X.Simulation analysis and match experiment on negative and positive pressures of pneumatic precision metering device for rapeseed. Int J Agric \& Biol Eng, 2014; 7(3): 1-12.

[3] Li X, Liao Q X, Yu J J, Shu C X, Liao Y T. Dynamic analysis and simulation on sucking process of pneumatic precision metering device for rapeseed. Journal of Food Agriculture \& Environment, 2012; 10(1): $450-454$.

[4] Liao Y T, Huang H D, Li X, Yu J J, Yan Q Y, Liao Q X. Effects of seed pre-soaking on sowing performance by pneumatic precision metering device for rapeseed. Transactions of the CSAM, 2013; 44(S1): 72-76. (in Chinese)

[5] Yasir S H, Liao Q X, Yu J, He D. Design and test of a pneumatic precision metering device for wheat. Agricultural Engineering International: CIGR Journal, 2012; 14(1): 16-25.

[6] Yang L, Yan B X, Cui T, Yu Y M, He X T, Liu Q W, et al. Globa overview of research progress and development of precision maize planters. Int J Agri \& Biol Eng, 2016; 9(1): 9-26.

[7] Zhang G Z, Zang Y, Luo X W, Wang Z M, Zhang Q, Zhang S S. Design and indoor simulated experiment of pneumatic rice seed metering device. Int J Agri \& Biol Eng, 2015; 8(4): 10-18.

[8] Liu L J, Yang H, Ma S C. Experimental study on performance of pneumatic seeding system. Int J Agri \& Biol Eng, 2016; 9(6): 84-90.

[9] Searle C L, Kocher M F, Smith J A, Blankenship E E. Field slope effects on uniformity of corn seed spacing for three precision planter metering systems. Applied Engineering in Agriculture, 2008; 24(5): 581-586.

[10] Cui T, Han D, Yin X, Li K, Xiao L, Yang L, et al. Design and experiment of inside-filling air-blowing maize precision seed metering device. Transactions of the CSAE, 2017; 33(1): 8-16. (in Chinese)

[11] Liu W Z, Zhao M Q, Wang W M, Zhao S J. Theoretical analysis and experiments of metering performance of the pneumatic seed metering device. Transactions of the CSAE, 2010; 26(9): 133-138. (in Chinese)

[12] Liao Q X, Wu F T, Tian B P. A type of precision metering device with positive pressure and negative pressure for rapeseed, 2008; Chinese Patent: CN201001269. (in Chinese)

[13] Duan H B, Liao Q X, Tian B P. The air chamber with negative pressure and positive pressure in the metering device. 2009; Chinese Patent: CN201332578. (in Chinese)

[14] Tian B P, Liao Q X, Huang H D, Shu C X, Duan H B, Li J B. Design of 2BFQ-6 combined seeder for Rapeseed. Transactions of the CSAM, 2008; 39(10): 211-213. (in Chinese)

[15] Fanigliulo R, Pochi D. Air-flow distribution efficiency of a precision drill used in the sowing of different graded seeds. Journal of Agricultural Science and Technology, 2011; B1: 655-662.

[16] Önal İ, Değirmencioğlu A, Yazgi A. An evaluation of seed spacing accuracy of a vacuum type precision metering unit based on theoretical considerations and experiments. Turk J Agric For, 2012; 36: 133-144.

[17] Ahmad E, Ghassemzadeh HR, Moghaddam M, Kim KU. Development of a precision seed drill for oilseed rape. Turk J Agric For, 2008; 32(5): $451-458$.

[18] Liao Q X, Li J B, Qin G L. Experiment of pneumatic precision metering device for rapeseed. Transaction of the CSAM, 2009; 40(8): 44-48. (in Chinese)

[19] Singh R, Singh G, Saraswat D. Optimisation of design and operational parameters of a pneumatic seed metering device for planting cottonseeds. Biosystems Engineering, 2005; 92(4): 429-38.

[20] Yazgi A, Degirmencioglu A. Optimisation of the seed spacing uniformity performance of a vacuum-type precision seeder using response surface methodology. Biosystems Engineering, 2007; 3(97): 347-356.

[21] Moody F H, Hancock J H, Wilkerson J B. Evaluating planter performance-cotton seed placement accuracy. ASAE Paper No. 03 1146, 2003. St Joseph, Michigan.

[22] Karayel D, Wiesehoff M, Özmerzi A, Müller J. Laboratory measurement of seed drill seed spacing and velocity of fall of seeds using high-speed camera system. Computers and Electronics in Agriculture, 2006; 50(2): 89-96.

[23] Li Y M, Zhao Z, Chen J, Xu L Z. Numerical simulation and experiment on the seeds pickup performance of precision air-suction seeder. Transactions of the CSAM, 2008; 39(10): 95-99. (in Chinese)

[24] Kumar G V P, Srivastava B, Nagesh D S. Modeling and optimization of parameters of flow rate of paddy rice grains through the horizontal rotating cylindrical drum of drum seeder. Computers and Electronics in Agriculture, 2009; 65(1): 26-35.

[25] Anantachar M, Prasanna G V, Kumar P G V, Guruswamy T. Neural 
network prediction of performance parameters of an inclined plate seed metering device and its reverse mapping for the determination of optimum design and operational parameters. Computers and Electronics in Agriculture, 2010; 72: 87-98.

[26] Anantachar M, Prasanna G V, Kumar P G V, Guruswamy T. Development of artificial neural network models for the performance prediction of an inclined plate seed metering device. Applied Soft Computing, 2011; 11: 3753-3763.

[27] Zhan Z, Yaoming L, Jin C, Lizhang X. Numerical analysis and laboratory testing of seed spacing uniformity performance for vacuum-cylinder precision seeder. Biosystems Engineering, 2010; 4(106): 344-51.

[28] Deng X Y, Li X, Shu C X, Hang H D, Liao Q X. Mathematical model and optimization of structure and operating parameters of pneumatic precision metering device for rapeseed. International Journal of Food, Agriculture and Environment, 2010; 8(1): 318-22.

[29] Wu F T, Liao Q X, Tian B P. Design of pneumatic precision metering device for rapeseed. Chinese Society of Science and Technology Annual Meeting Agriculture Branch Thesis Series, 2006; pp.35-38.

[30] Cong J J, Yu J J, Cao X Y, Liao YT, Liao Q X. Design of dual-purpose pneumatic precision metering device for rape and wheat. Transactions of the CSAM, 2014; 45(1): 46-52. (in Chinese)

[31] Liao Q X, Zhang M, Yu J J, Liu X H. Pneumatic centralized metering device for rapeseed. Transactions of the CSAM, 2011; 42(8): 30-34. (in Chinese)

[32] Li M, Liao Q X, Liao Y T, Shu C X, Li L. Analysis on seeding process of pneumatic cylinder-type centralized rapeseed precision metering device. Transactions of the CSAE, 2014; 30(23): 17-27.

[33] Liao Y T, Wang L, Liao Q X. Design and test of an inside-filling pneumatic precision centralized seed-metering device for rapeseed. Int J Agric \& Biol Eng, 2017; 10(2): 56-62.

[34] Yazgi A, Degirmencioglu A. Measurement of seed spacing uniformity performance of a precision metering unit as function of the number of holes on vacuum plate. Measurement, 2014; 56: 128-135.

[35] Lü J Q, Yang Y, Li Z H, Qin S Q, Li J C, Liu Z Y. Design and experiment of an air-suction potato seed metering device. Int Agri \& Biol Eng, 2016; 9(5): 33-42.

[36] Barut Z B, Zmerzü A. Effect of different operating parameters on seed holding in the single seed metering unit of a pneumatic planter. Turk $\mathrm{J}$ Agric For, 2004; 28: 435-441. 